\title{
What Are the Functional Results and Complications With Long Stem Hemiarthroplasty in Patients With Metastases to the Proximal Femur?
}

\author{
Joel R. Peterson MA, Alexander P. Decilveo BA, Ian T. O'Connor BS, \\ Ivan Golub BS, James C. Wittig MD
}

Published online: 6 April 2016

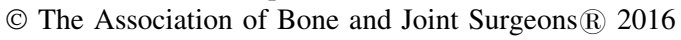

\begin{abstract}
Background Traditional treatments for pathological fractures of the proximal femur resulting from metastatic bone disease include fixation with intramedullary nailing supplemented with polymethylmethacrylate, osteosynthesis with a plate-screw construct and polymethylmethacrylate, or endoprosthetic reconstruction. Despite the frequent practice of these treatments, treatment outcomes have not been rigorously compared. In addition, very few studies examine specific approaches to endoprosthetic reconstruction such as long stem hemiarthroplasty.
\end{abstract}

Each author certifies that he or she, or a member of his or her immediate family, has no funding or commercial associations (eg, consultancies, stock ownership, equity interest, patent/licensing arrangements, etc) that might pose a conflict of interest in connection with the submitted article.

All ICMJE Conflict of Interest Forms for authors and Clinical

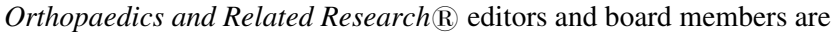
on file with the publication and can be viewed on request.

Clinical Orthopaedics and Related Research $\AA$ neither advocates nor endorses the use of any treatment, drug, or device. Readers are encouraged to always seek additional information, including FDAapproval status, of any drug or device prior to clinical use. Each author certifies that his or her institution approved the human protocol for this investigation, all investigations were conducted in conformity with ethical principles of research, and informed consent for participation in the study was obtained.

This work was performed at Hackensack University Medical Center, Hackensack, NJ, USA.

\section{J. R. Peterson}

Rutgers Robert Wood Johnson Medical School, 125 Paterson

Street, New Brunswick, NJ 08901, USA

A. P. Decilveo, I. T. O’Connor, I. Golub, J. C. Wittig ( $\square)$

John Theurer Cancer Center, Hackensack University Medical

Center, Hackensack, NJ, USA

e-mail: Drjameswittig@gmail.com
Questions/purposes This study examines survival, functional outcomes, and complications associated with long stem hemiarthroplasty in a small group of patients treated for impending and actual pathologic fractures of the proximal femur resulting from metastatic bone disease.

Methods Between 2012 and 2015, 21 patients were treated with long stem cemented hemiarthroplasty in 22 limbs. During that time, indications for this approach included lesions from metastases, myeloma, or lymphoma involving the proximal femur that resulted in an impending or actual pathological fracture. An impending fracture was classified as a painful lesion with at least 50\% cortical erosion. During the study period, six patients with proximal femoral metastases not deemed to meet these indications were treated with other surgical approaches such as intramedullary nailing supplemented with polymethylmethacrylate and osteosynthesis with a plate-screw construct and polymethylmethacrylate. Mortality was tracked through medical records and phone calls to the patients and their families. Followup for the entire group of patients $(n=22)$ ranged from 1 to 27 months with a mean duration of 11 months. For patients with at least 1 year of followup $(\mathrm{n}=11)$, the mean duration was 18 months (range, 12-27 months) and for patients with less than 1 year of followup ( $\mathrm{n}=11$ ), the mean duration was 3 months (range, 1-11 months). Functional outcomes were evaluated according to the Musculoskeletal Tumor Society (MSTS) scoring system for lower extremities, the Eastern Cooperative Oncology Group (ECOG) Scale of Performance Status, and the Karnofsky Performance Scale (KPS) Index. Scores and complications were determined by direct patient examination, retrospective chart review, review of a longitudinally maintained institutional database, and followup phone calls.

Results Ten patients died of disease within the followup period. Before surgery, the median total MSTS score for the entire group of patients $(\mathrm{n}=22)$ was 4.5 (range, $0-23$ ), 
the median ECOG score was 3.5 (range, 1-4), and the median KPS score was 40 (range, 30-70). Postoperatively, the median total MSTS score (measured at most recent followup) for the entire group of patients was 21 (range, 530 ), the median ECOG score was 2 (range, 0-3, 68\% $\leq 2$ ), and the median KPS score was 60 (range, 40-100). For the 11 patients with at least 1 year of followup, the median total MSTS score (measured at most recent followup) was 27 (range, 21-30), the median ECOG score was 1 (range, $0-2,100 \% \leq 2$ ), and the median KPS score was 80 (range, 60-100). For the remaining 11 patients with less than 1 year of followup, the median total MSTS score (measured at most recent followup) was 11 (range, 5-25), the median ECOG score was 3 (range, $1-3,36 \% \leq 2$ ), and the median KPS score was 40 (range, 40-80). Complications included one periprosthetic fracture resulting from a fall, three cases of radiation-induced edema, and two cases of sciatica that developed unrelated to the procedure.

Conclusions Long stem cemented hemiarthroplasty results in fair levels of function in a complex population of patients whose prognosis is sometimes measured only in months and who otherwise might be disabled by their metastatic lesions. Comparative trials applying consistent indications and inclusion criteria should be performed between this approach and fixation with intramedullary nailing supplemented with polymethylmethacrylate as well as osteosynthesis with a plate-screw construct and polymethylmethacrylate.

Level of Evidence Level IV, therapeutic study.

\section{Introduction}

Pathologic fracture of the femur is an extremely debilitating complication of metastatic disease and multiple sources report that mortality quickly follows this diagnosis in many patients [1, 3, 28, 33, 34]. Of patients with advanced cancer, $50 \%$ develop bone metastases and one-third of all metastatic lesions occur in the proximal femur [8, 20, 32]. As many as $29 \%$ of these patients develop pathologic fractures and $65 \%$ of all pathologic fractures requiring surgery occur in the femur [8]. One-year survival rates after surgical treatment for metastatic lesions of the long bones or proximal femur range from $17 \%$ to $30 \%$ and 2-year survival rates are as low as 6\% [28]. Treatment of pathologic fracture, therefore, is intended to restore function of the affected limb, relieve pain, improve quality of life, and facilitate custodial care as well as additional medical testing and treatment as quickly as possible. Substantial variation exists in approaching treatment for impending or actual pathologic fractures of the proximal femur [31]. Surgical interventions for pathologic fractures of the proximal femur resulting from metastatic bone disease traditionally include fixation with intramedullary nailing supplemented with polymethylmethacrylate bone cement, osteosynthesis with a plate-screw construct and polymethylmethacrylate, or endoprosthetic reconstruction [31]. Despite the frequent practice of these treatments, treatment outcomes have not been rigorously compared [31].

Endoprosthetic reconstruction has been shown to improve ambulatory status and decrease pain in patients with pathologic fractures of the proximal femur $[1,5,6,15$, 18, 19, 23]. The procedure also enables the surgeon to remove all gross disease, minimize recurrence and hardware failure, and protect the rest of the femur against progressing disease [2]. Disadvantages of endoprosthetic reconstruction include hip dislocation, leg length discrepancy, blood loss during the procedure, and intraoperative hypotension. Very few studies examine specific approaches to endoprosthetic reconstruction such as long stem hemiarthroplasty.

The purpose of this study therefore was to examine survival, functional outcomes, and complications associated with long stem hemiarthroplasty in a small group of patients treated for impending or actual pathologic fractures of the proximal femur resulting from metastatic bone disease.

\section{Patients and Methods}

Between 2012 and 2015, 21 patients with metastatic lesions of the proximal femur were treated for actual or impending fractures in 22 limbs with long stem cemented hemiarthroplasty (Fig. 1). One patient underwent bilateral hemiarthroplasties 5 months apart. Indications for this approach included lesions from metastases, myeloma, or lymphoma involving the proximal femur that resulted in an impending or actual pathological fracture. An impending fracture was classified as a painful lesion with at least $50 \%$ cortical erosion. During the study period, six patients with proximal femoral metastases not deemed to meet these indications were treated with other surgical approaches such as intramedullary nailing supplemented with polymethylmethacrylate and osteosynthesis with a plate-screw construct and polymethylmethacrylate. Contraindications included massive destruction of the proximal femur and/or soft tissue components, extensive acetabular disease, extensive pulmonary disease, minimal ambulation, an isolated lesion with no history of cancer, high risk of infection, and potential noncompliance with postoperative protocols.

During this time period, there was one patient with extraosseous disease who was treated with an intramedullary rod because of issues with compliance and infection risk. No patients with metastatic disease during this time 


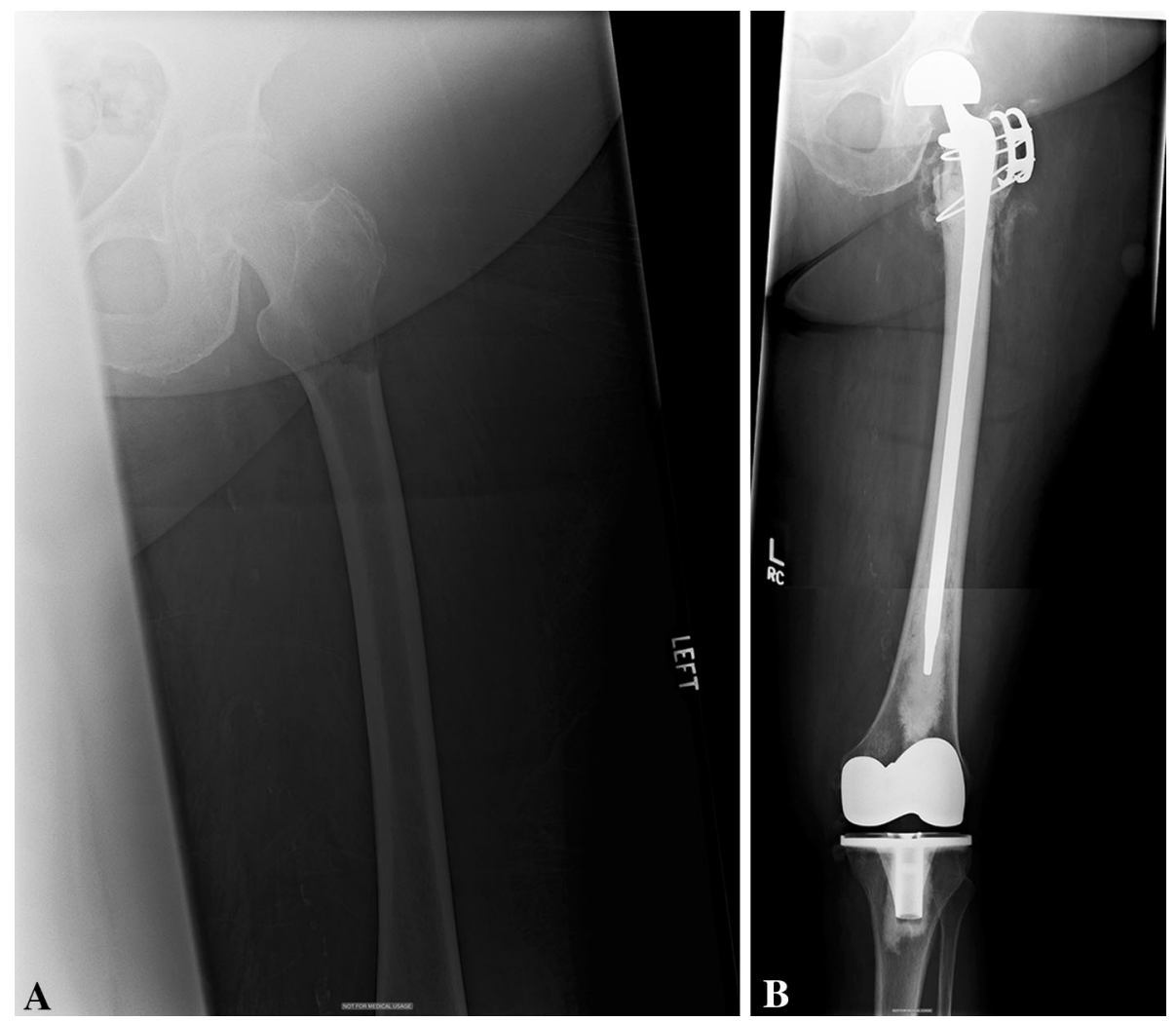

Fig. 1A-B A 72-year-old woman with metastatic breast adenocarcinoma was treated for a pathologic fracture with a long stem hemiarthroplasty. (A) Preoperative radiographs show an impending pathologic fracture of the left proximal femur. (B) Postoperative radiographs show fixation of the impending fracture with a long stem

period were treated with proximal femoral resection and replacement.

Mortality was tracked through medical records and phone calls to the patients and their families. Followup for the entire group of patients $(n=22)$ ranged from 1 to 27 months with a mean duration of 11 months. For patients with at least 1 year of follow up $(\mathrm{n}=11)$, the mean duration was 18 months (range, 12-27 months) and for patients with less than 1 year of followup $(n=11)$, the mean duration was 3 months (range, 1-11 months). The patients included 11 men aged 43 to 87 years and 10 women aged 38 to 85 years (Table 1). Patients presented with lesions of the subtrochanteric, intertrochanteric, greater trochanteric, lesser trochanteric, femoral neck, or head regions. Some patients had tumors that spanned more than one region. Patients with impending fractures $(n=6$ limbs) had lytic or combined lytic and blastic painful lesions with at least some degree of cortical erosion or penetration. No patients had large areas of segmental bone loss. Patients with actual pathological fractures $(n=16$ limbs) had minimal to mild displacement and angulation. The primary tumor etiologies included myeloma $(n=6)$, prosthesis in place. Cables were placed in this particular patient to stabilize the greater trochanter. A total knee prosthesis from prior surgery is also noted. Proximal and distal radiographs superimposed using photograph-editing software to appreciate the extent of the operation.

breast adenocarcinoma $(\mathrm{n}=4)$, renal adenocarcinoma $(\mathrm{n}=2)$, prostate adenocarcinoma $(\mathrm{n}=2)$, lung adenocarcinoma $(\mathrm{n}=2)$, adenocarcinoma from an unknown location $(\mathrm{n}=2)$, endometrial adenocarcinoma $(\mathrm{n}=1)$, colon adenocarcinoma $(n=1)$, urothelial adenocarcinoma $(\mathrm{n}=1)$, and chronic lymphocytic leukemia $(\mathrm{n}=1)$. Two patients underwent preoperative radiation therapy, five patients underwent postoperative radiation therapy, and one patient underwent both preoperative and postoperative radiation therapy.

After removal of all gross tumor, a long stem bipolar $(\mathrm{n}=21)$ or unipolar $(\mathrm{n}=1)$ prosthesis was inserted and cemented. The prostheses used in this study included straight femoral stems manufactured by Zimmer Inc (Warsaw, IN, USA; $\mathrm{n}=16$ ), bowed femoral stems manufactured by Stryker Corp (Kalamazoo, MI, USA; $n=3$ ), bowed femoral stems manufactured by Biomet Inc. (Warsaw, IN; $n=2$ ), and an S-shaped bowed femoral stem manufactured by LinkBio Corp (Rockaway, NJ, USA; $\mathrm{n}=1$ ) (Table 2). Femoral stem length ranged from 200 to $350 \mathrm{~mm}$ with a mean stem length of $270 \mathrm{~mm}$ and $64 \%$ of patients were treated with a $300-$ or $350-\mathrm{mm}$ stem. 


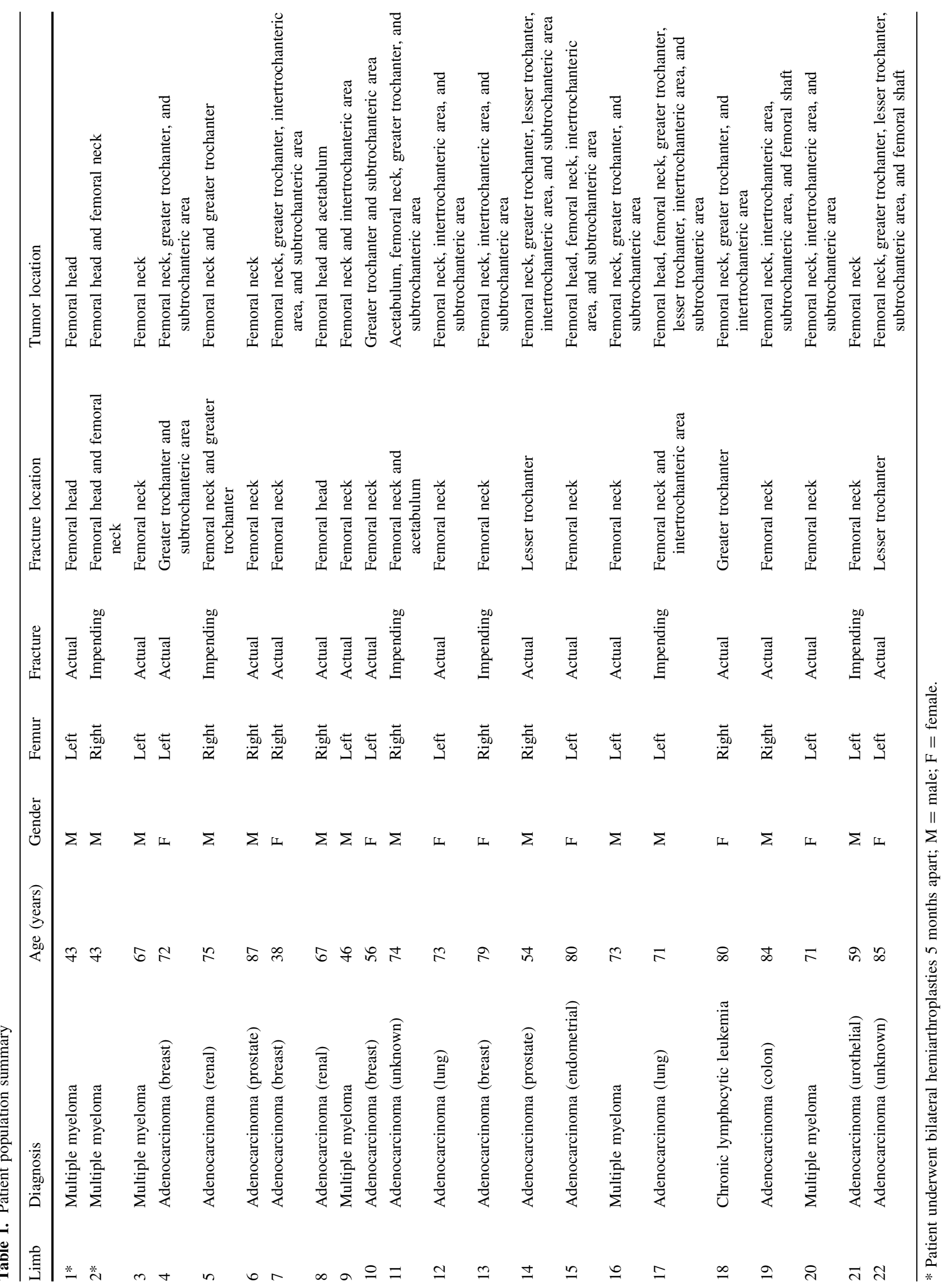


Table 2. Surgical summary

\begin{tabular}{|c|c|c|c|c|c|c|c|}
\hline Limb & $\begin{array}{l}\text { Operation time } \\
\text { (minutes) }\end{array}$ & $\begin{array}{l}\text { Preoperative } \\
\text { hematocrit }(\%)\end{array}$ & $\begin{array}{l}\text { Patient blood loss } \\
(\mathrm{mL})\end{array}$ & $\begin{array}{l}\text { Blood } \\
\text { transfusion }(\mathrm{mL})\end{array}$ & Prosthesis manufacturer & $\begin{array}{l}\text { Stem length } \\
(\mathrm{mm})\end{array}$ & $\begin{array}{l}\text { Stem } \\
\text { shape }\end{array}$ \\
\hline $1 *$ & 94 & 33.9 & 400 & 350 & $\begin{array}{l}\text { Zimmer Inc (Warsaw, IN, } \\
\text { USA) }\end{array}$ & 300 & Straight \\
\hline $2 *$ & 93 & 41.4 & 250 & None & Zimmer Inc & 300 & Straight \\
\hline 3 & 100 & 35.6 & 200 & 400 & Zimmer Inc & 250 & Straight \\
\hline 4 & 142 & 28.8 & 250 & 300 & Zimmer Inc & 300 & Straight \\
\hline 5 & 126 & 39.4 & 1000 & 1234 & $\begin{array}{l}\text { Stryker Corp (Kalamazoo, } \\
\text { MI, USA) }\end{array}$ & 300 & Bowed \\
\hline 6 & 112 & 32.5 & 500 & 400 & Stryker Corp & 250 & Bowed \\
\hline 7 & 113 & 30.7 & 300 & 640 & Zimmer Inc & 250 & Straight \\
\hline 8 & 188 & 39.2 & 1000 & 1200 & Zimmer Inc & 300 & Straight \\
\hline 9 & 100 & 38.3 & 300 & 300 & Zimmer Inc & 200 & Straight \\
\hline 10 & 127 & 37.5 & 250 & None & $\begin{array}{l}\text { Biomet Inc (Warsaw, IN, } \\
\text { USA) }\end{array}$ & 250 & Bowed \\
\hline 11 & 163 & 28.6 & 500 & 900 & Zimmer Inc & 250 & Straight \\
\hline 12 & 93 & 28.8 & 500 & 680 & Zimmer Inc & 300 & Straight \\
\hline 13 & 109 & 38.0 & 100 & None & Stryker Corp & 300 & Bowed \\
\hline 14 & 107 & 43.0 & 100 & 128 & Zimmer Inc & 300 & Straight \\
\hline 15 & 132 & 34.3 & 250 & None & Zimmer Inc & 250 & Straight \\
\hline 16 & 130 & 34.8 & 300 & 395 & Zimmer Inc & 300 & Straight \\
\hline 17 & 150 & 30.2 & 400 & 400 & Zimmer Inc & 300 & Straight \\
\hline 18 & 116 & 32.5 & 200 & 400 & Zimmer Inc & 300 & Straight \\
\hline 19 & 102 & 37.3 & 250 & 500 & $\begin{array}{l}\text { LinkBio Corp (Rockaway, } \\
\text { NJ, USA) }\end{array}$ & 300 & $\begin{array}{l}\text { S-shape } \\
\text { bowed }\end{array}$ \\
\hline 20 & 112 & 25.6 & 350 & 400 & Zimmer Inc & 250 & Straight \\
\hline 21 & 105 & 40.8 & 250 & 300 & Biomet Inc & 350 & Bowed \\
\hline 22 & 130 & 35.8 & 250 & None & Zimmer Inc & 300 & Straight \\
\hline
\end{tabular}

* Patient underwent bilateral hemiarthroplasties 5 months apart.

\section{Surgical Technique}

A posterolateral approach to the hip was performed. The hip external rotators were released from their insertion and were each sequentially tagged with a suture and retracted. The hip capsule was then opened in a T-shaped manner and each leaf tagged with a suture.

The hip was dislocated, and the femoral neck cut was performed from the piriformis fossa to approximately $2 \mathrm{~cm}$ proximal to the lesser trochanter using the appropriate guide. All gross tumor tissue in the proximal femur was removed with pituitary rongeurs, hand curettes, and gynecological curettes. All intramedullary contents of the proximal femur extending distal to the subtrochanteric region were removed and the endosteal surface of the canal was vigorously curetted to remove all gross disease. The canal was thoroughly cleansed with a pulsatile canal irrigator and brush. A ball-tipped guidewire was placed down the femoral canal to the most distal aspect of the femur, and the femur was reamed in 1-mm increments from $8 \mathrm{~mm}$ up to $2 \mathrm{~mm}$ greater than the diameter of the stem. In some instances, an extra $1 \mathrm{~mm}$ of reaming was necessary if there was difficulty with the trial insertion as a result of the length of the bow of the stem matching with the length of the femur. The proximal femur was subsequently broached, and the length of the canal was measured using the balltipped guidewire. The appropriate length stem was trialed to confirm fit and then removed.

The canal was again irrigated and brushed with sterile normal saline by pulsatile lavage. Three bags of polymethylmethacrylate were mixed and allowed to cure to a doughy consistency before being injected into the femoral canal in a retrograde manner and without pressurization. The final femoral component was placed in a slow and controlled manner and the cement was then allowed to fully cure. This cementing technique is thought to reduce the risk of cardiopulmonary collapse as a result of venous extravasation from the canal. A femoral head was trialed with stability achieved in all positions without dislocation. The trial femoral head was dislocated and removed and the 
final femoral head was malleted into position to engage the Morse taper. The hip was subsequently reduced and the capsule and external rotators reapproximated. The wound was closed, bandages applied, and a hip abduction pillow placed. No patients required an additional incision to remove the tumor and fix the prosthesis with cement.

\section{Assessment of Outcomes}

Patients were admitted to the hospital postoperatively for approximately 3 days and subsequently discharged to either rehabilitation or home. All patients were permitted to be weightbearing as tolerated on postoperative Day 1 and instructed to follow hip precautions for 6 weeks. Patients were followed up in the office at approximately 2 weeks, 6 weeks, and 3 months from surgery. Subsequently, patients were followed every 3 to 4 months during the time period of the study. Whole femur AP and lateral plain radiographs were obtained at each visit. Most patients were treated by medical oncologists at our institution and we therefore had access to their electronic medical oncology records. As earlier noted, mortality was tracked through medical records and phone calls to the patients and their families. Patient limb function was evaluated according to the Musculoskeletal Tumor Society (MSTS) scoring system for lower extremities, the Eastern Cooperative Oncology Group (ECOG) Scale of Performance Status, and the Karnofsky Performance Scale (KPS) Index. The MSTS scoring system for lower extremities covers six domains including pain, function, emotional acceptance, supports, walking, and gait [7]. Each domain is given a score of 0 to 5 with 5 representing normal function such that the maximum total MSTS score is 30 [7]. The ECOG score describes patients' functional status on a scale of 0 (fully active) to 5 (dead) based on the patients' ability to care for themselves, their daily activity, and their physical ability [21]. The KPS score describes patients' functional status on a scale of 0 (dead) to 100 (fully active) based on their ability to perform daily activities and how much assistance is required for them to do so [14]. MSTS scores, ECOG scores, KPS scores, and complications were determined by direct patient examination, retrospective chart review, review of a longitudinally maintained institutional database, and followup phone calls.

\section{Results}

A total of 10 of the 21 patients died of disease within the followup period; nine deaths occurred within 1 year of surgery and one death occurred 1 year after surgery (Table 3). The deaths occurred at a median of 2.5 months (range, 1-12 months). None of the deaths were related directly to the procedures itself.

Before surgery, the median total MSTS score for the entire group of patients was 4.5 (range, 0-23), the median ECOG score was 3.5 (range, 1-4), and the median KPS score was 40 (range, 30-70) (Table 4). Postoperatively, the median total MSTS score (measured at most recent followup) for the entire group of patients was 21 (range, 530 ), the median ECOG score was 2 (range, 0-3, 68\% $\leq 2$ ), and the median KPS score was 60 (range, 40-100). For the 11 patients with at least 1 year of followup, the median total MSTS score (measured at most recent followup) was 27 (range, 21-30), the median ECOG score was 1 (range, $0-2,100 \% \leq 2$ ), and the median KPS score was 80 (range, 60-100). For the remaining 11 patients with less than 1 year of followup, the median total MSTS score (measured at most recent followup) was 11 (range, 5-25), the median ECOG score was 3 (range, $1-3,36 \% \leq 2$ ), and the median KPS score was 40 (range, 40-80).

One major postoperative complication occurred when a patient fell 3 months after surgery and endured a segmental diaphyseal periprosthetic femur fracture requiring surgical fixation with Dall-Miles cables (Aspen Surgical, Caledonia, MI, USA) (Fig. 2). Minor complications including radiation-induced edema and myositis were reported but responded to therapy and did not require significant alteration of the treatment plan. In addition, two patients developed sciatica 10 and 18 months after surgery unrelated to the procedure (one patient was in a car accident). Both of these patients reported no pain before the onset of sciatica. There were no thromboembolic events, cementassociated oxygen desaturation events, cardiac arrests, hypotension, death, or any other intraoperative complications (Table 2). No postoperative cardiopulmonary or neurological complications were reported. There were no infections, hip dislocations, or instances of prosthetic loosening. There were no cases of hardware failure or local disease progression.

\section{Discussion}

Pathologic fracture of the proximal femur causes severe pain and loss of ambulatory function in patients with advanced cancer. In the setting of modern life-extending advances in adjuvant therapies, surgical intervention aims to provide stable fixation for pain relief, immediate weightbearing, and restoration of ambulatory function; fixation should outlast the patient's life expectancy and minimize the risk of complications [11, 13, 16, 33]. Endoprosthetic reconstruction is a surgical modality commonly used to reach these goals, but the outcomes of specific approaches such as stem length, cement use, and 


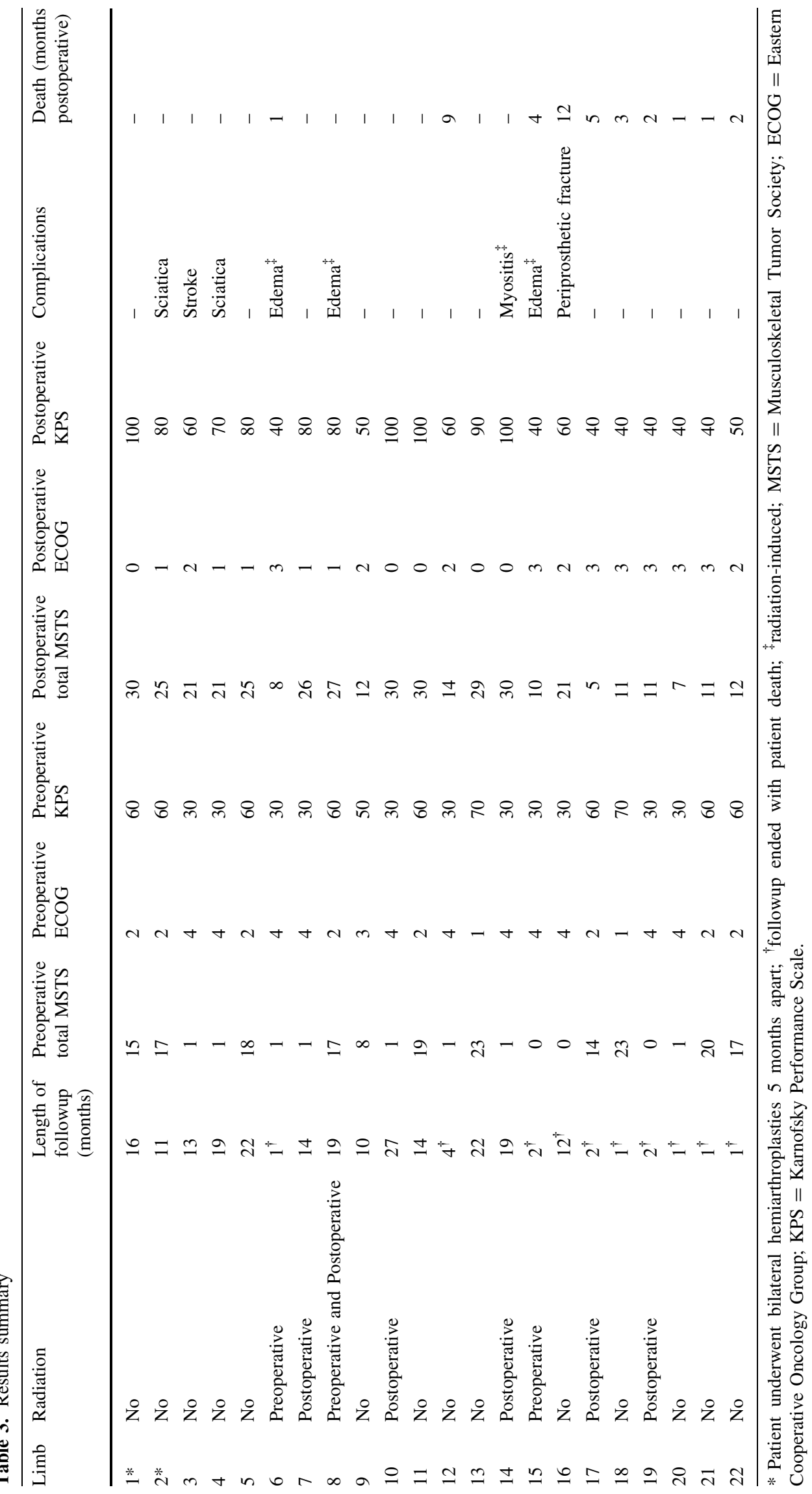




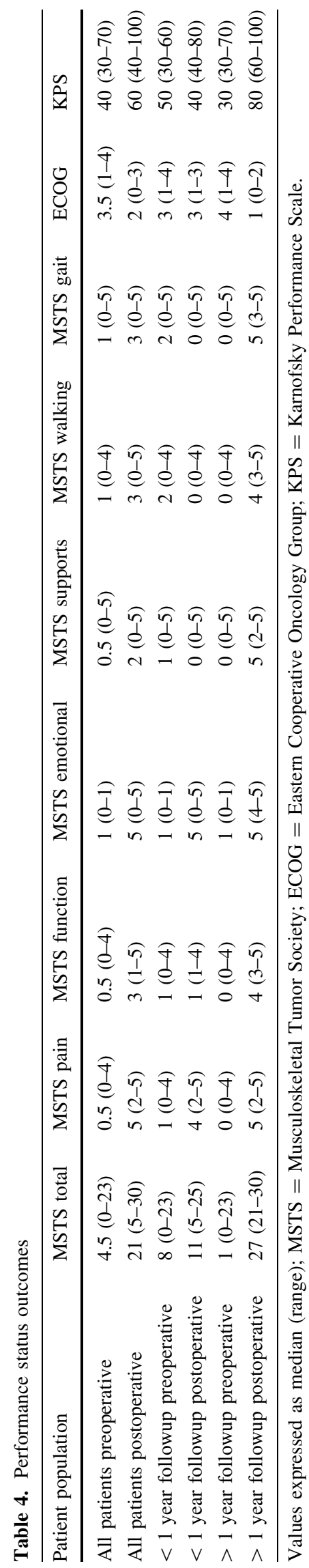

type of prosthesis continue to be controversial [15, 31, 35]. This study seeks to elucidate the survival, functional outcomes, and complications associated with long stem cemented hemiarthroplasty in a small group of patients treated for impending and actual pathologic fractures of the proximal femur resulting from metastatic bone disease. A total of 10 of the 21 patients died of disease during the followup period; none of the deaths were directly attributable to endoprosthetic reconstruction. The MSTS scores, ECOG scores, and KPS scores were fair, and most patients saw significant improvement in pain and functional mobility with few complications.

This study had a number of limitations. First, the small number of patients is not likely to adequately represent the population distribution; uncommon complications and outcomes are less likely to be detected by a study of this size. Accordingly, we found median measurements to be the most accurate representation of the data, but this will limit the comparison to studies reporting mean values. The small size, however, allowed for all patients to be treated by the same surgeon using the same technique, which was critical to the goal of the study. Second, the study has no control group, which limits the meaningful comparison of surgical outcomes. Although the standardized scores allow some degree of analysis in the context of prior research, future studies should aim to more directly compare the outcomes of long stem hemiarthroplasty with outcomes of other surgical approaches. Third, the study is limited by selection bias. A total of six of 27 patients were treated with alternative therapy during the study period. Metastatic disease has a complicated and variable presentation, and appropriate treatment must be customized for each patient. Exclusion criteria leading to this selection included massive destruction of the proximal femur and/or soft tissue components, extensive acetabular disease, extensive pulmonary disease, minimal ambulation, an isolated lesion with no history of cancer, high risk of infection, and potential noncompliance with postoperative protocols. Fourth, the performance status scoring systems used (MSTS, ECOG, KPS) provide valuable quantification of functionality but are also a source of assessment bias because they do not adequately address the overall health and quality of life of these patients. These are important and complex parameters to consider in addition to function, although given the number of deaths within 1 year of surgery, it should be noted that many patients are in a palliative stage of care. Finally, the study is limited by the short length of followup. Maximal benefit is unlikely to be achieved in patients who died within 3 months of surgery, which would skew our results toward overall lower functional outcomes. However, the outcomes in these patients are still clinically important given the poor prognosis and presentation of comorbidities with metastatic disease. 

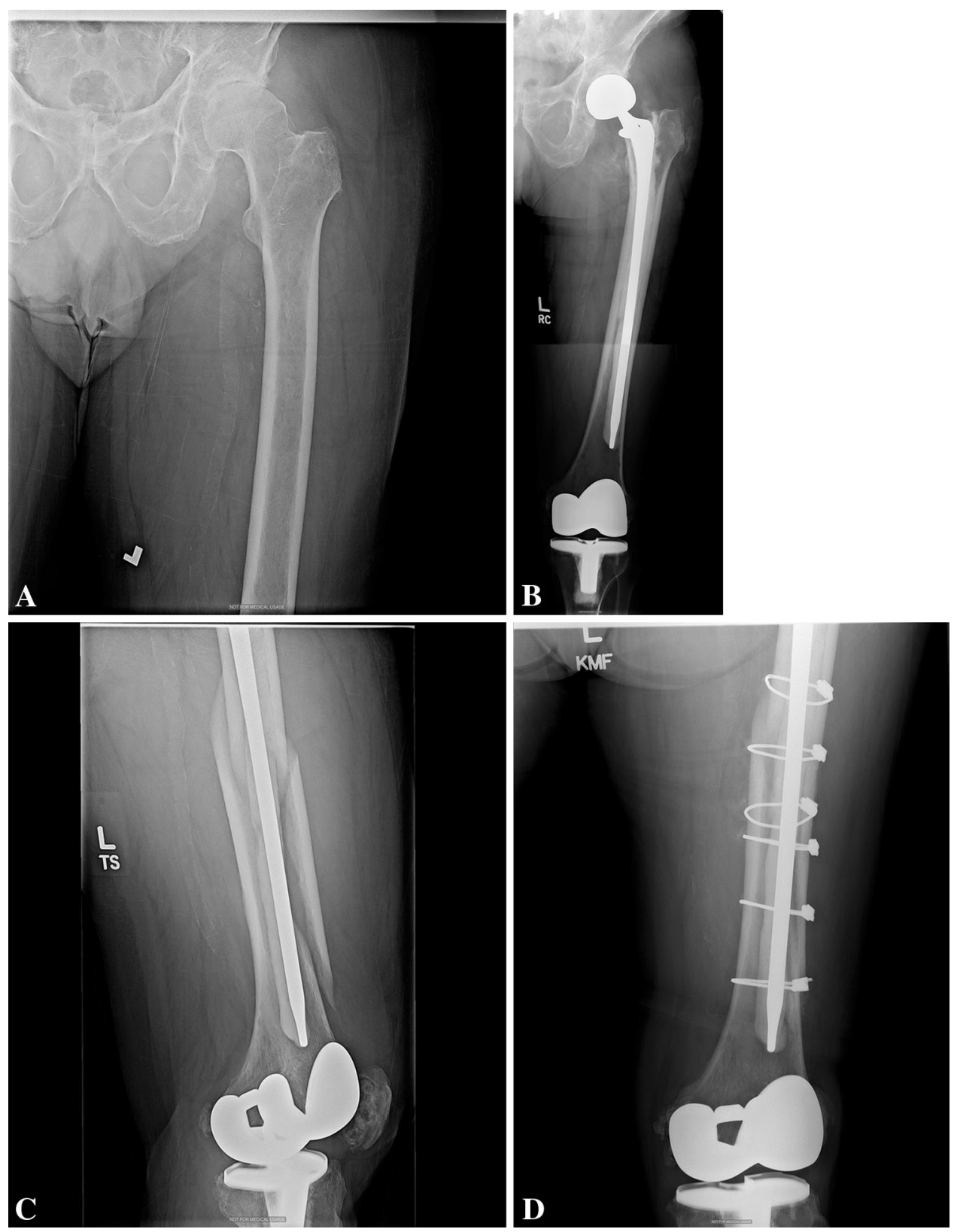

Fig. 2A-D A 73-year-old man with multiple myeloma was treated for a pathologic fracture with a long stem hemiarthroplasty. (A) Preoperative radiographs show a pathologic fracture of the left proximal femur. (B) Postoperative radiographs show fixation of the fracture with a long stem prosthesis in place. A total knee prosthesis

This is a complex group of patients, and for many of them, a proximal femoral pathologic fracture is an endof-life event. Not surprisingly then, nearly half of the patients in this series (10 of 21) died within 1 year of the hip reconstruction. This is comparable to the survivorship reported by Harvey et al. [10], in which overall patient survival at 1 year after undergoing endoprosthetic reconstruction or intramedullary nail fixation for proximal femur from prior surgery is noted. Proximal and distal radiographs are superimposed using photograph-editing software to appreciate the extent of the operation. (C) A fall 3 months postoperatively resulted in a segmental periprosthetic diaphyseal fracture. (D) The patient was treated with surgical reduction and fixation with Dall-Miles cables.

metastases was $51 \%$. Hattori et al. [11] reported a 1-year survival rate of $69 \%$, although this represents only eight patients who underwent endoprosthetic reconstruction. Sarahrudi et al. [28] reported a 1-year survival rate of $17 \%$ in a population in which 94 patients were treated with intramedullary nail fixation, 23 with endoprosthetic reconstruction, and 22 with open reduction and internal fixation. In this study, $76.7 \%$ of patients presented with 
Table 5. Performance status outcomes from other studies

\begin{tabular}{|c|c|c|c|}
\hline Study & Operative strategy & $\begin{array}{l}\text { Performance } \\
\text { status }\end{array}$ & Outcome \\
\hline \multirow[t]{2}{*}{$\begin{array}{l}\text { Harvey et al., } 2012 \\
\quad[10]\end{array}$} & $\begin{array}{l}\text { Endoprosthetic reconstruction (proximal femur reconstruction) } \\
\qquad(\mathrm{n}=113)\end{array}$ & Mean MSTS & 21 (range, 12-27) \\
\hline & Intramedullary nail $(\mathrm{n}=46)$ & & 24 (range, 8-30) \\
\hline \multirow[t]{3}{*}{$\begin{array}{l}\text { Steensma et al., } 2012 \\
\text { [30] }\end{array}$} & $\begin{array}{l}\text { Endoprosthetic reconstruction }(\mathrm{n}=197) \\
\text { - Long stem cemented hemiarthroplasty }(\mathrm{n}=163) \\
\text { - Proximal FEMUR RECONSTRUCTION }(\mathrm{n}=33) \\
\text { - Standard length hemiarthroplasty }(\mathrm{n}=1)\end{array}$ & $\mathrm{ECOG} \leq 2$ & $61 \%$ \\
\hline & Intramedullary nail $(\mathrm{n}=82)$ & & $88 \%$ \\
\hline & Open reduction and internal fixation $(\mathrm{n}=19)$ & & $47 \%$ \\
\hline Potter et al., 2009 [25] & $\begin{array}{l}\text { Endoprosthetic reconstruction (proximal femur reconstruction) } \\
\quad(\mathrm{n}=39)\end{array}$ & Mean MSTS & 20 (range, $13-27$ ) \\
\hline Selek et al., 2008 [29] & $\begin{array}{l}\text { Endoprosthetic reconstruction }(\mathrm{n}=45) \\
\text { - Proximal femur reconstruction }(\mathrm{n}=35) \\
\text { - Long stem cemented hemiarthroplasty }(\mathrm{n}=5) \\
\text { - Thompson prosthesis }(\mathrm{n}=5)\end{array}$ & Mean MSTS & $\begin{array}{l}\text { Pathological fracture at } 2 \text { months: } \\
14.06 \\
\text { Impending fracture at } 2 \text { months: } \\
\quad 16.64 \\
\text { Surviving patients at } 1 \text { year: } 19.8\end{array}$ \\
\hline
\end{tabular}

MSTS = Musculoskeletal Tumor Society; ECOG = Eastern Cooperative Oncology Group.

multiple metastases at the time of fracture. Selek et al. [29] reported a 1-year survivorship of $27 \%$ after endoprosthetic reconstruction. Our results are consistent with typical survival rates, but the apparent disparity in survivorship in recent research reaffirms the need for detailed reporting of patient preoperative status and a more rigorous examination of specific surgical techniques.

Most patients who present with proximal femoral bone metastases have severe pain with ambulation or are unable to walk. Long stem hemiarthroplasty in this series restored functional ambulation and relieved pain in most of the patients. These improvements are particularly evident in patients who reached at least 1 year of followup as shown by the increased MSTS subscores and total score (Table 4). Of the patients with less than 1 year of followup, nine died of disease. Six of these patients died within 3 months of surgery. The performance status scores for this group of patients are lower likely as a result of disease and comorbidities, short length of recovery time, or a combination of these factors. We believe the functional status of this group of patients is clinically important and that these results may be particularly useful in the palliative care of patients with limited predicted lifespans. Of note is the substantial improvement in the MSTS pain subscore in this group of patients despite lack of improvement in mobility. Although there was no comparator group in this series, we believe these outcomes compare favorably to those reported for other forms of fixation, namely intramedullary nailing, osteosynthesis, and alternative forms of endoprosthetic reconstruction. In peer-reviewed studies regarding outcomes for surgical treatment of metastatic bone disease of the proximal femur, the methods of functional status assessment are extremely inconsistent and often subjective, although some have used validated assessment tools (Table 5). It should be noted that the incorporation of these assessments is also inconsistent or not described, which limits the value of comparison. Furthermore, no study reports MSTS subscores, which, as stated previously, may be particularly relevant in the clinical decision-making for patients with short expected lifespans. These findings highlight the need for rigorous comparison trials for approaches to surgical fixation that apply consistent indications and inclusion criteria as well as a standardized assessment method.

Complications in this series were uncommon, although this must be considered major surgery by any definition, and these patients can be medically complex. Alternative treatments have been associated with dislocation, infection, nonunion, and disease progression, often requiring reoperation. Intraoperative complications such as hypotension, oxygen desaturation, embolization, and cardiac arrest have also been reported [2, 9, 12, 22, 24, 26-28]. Of note, Barwood et al. [4] reported acute oxygen desaturation and hypertension in 11 of 45 patients treated with intramedullary nail fixation for metastatic tumors of the femur with actual or impending fractures. Of these 11 patients, three died and two required intensive postoperative care. Complications arising from other surgical approaches to this problem are relatively common (Table 6). By comparison, our findings are relatively promising; we observed no 
Table 6. Failure rates and complications from other studies

\begin{tabular}{|c|c|c|c|}
\hline Study & Operative strategy & $\begin{array}{l}\text { Failure } \\
\text { rate }\end{array}$ & Complication \\
\hline \multirow[t]{2}{*}{ Harvey et al., 2012 [10] } & Endoprosthetic reconstruction $(\mathrm{n}=113)$ & $0 \%$ & $\begin{array}{l}\text { Dislocation }(\mathrm{n}=10) \\
\text { Infection }(\mathrm{n}=10)\end{array}$ \\
\hline & Intramedullary nail $(\mathrm{n}=46)$ & $11 \%$ & $\begin{array}{l}\text { Nonunion }(n=4) \\
\text { Nonunion and nail breakage }(n=6) \\
\text { Infection }(n=1) \\
\text { Painful hardware }(n=1)\end{array}$ \\
\hline \multirow[t]{3}{*}{$\begin{array}{l}\text { Steensma et al., } 2012 \\
\text { [30] }\end{array}$} & Endoprosthetic reconstruction $(\mathrm{n}=197)$ & $3 \%$ & $\begin{array}{l}\text { Dislocation }(n=5) \\
\text { Painful disease progression }(n=1)\end{array}$ \\
\hline & Intramedullary nail $(\mathrm{n}=82)$ & $6 \%$ & $\begin{array}{l}\text { Nonunion/painful progression }(\mathrm{n}=3) \\
\text { Nonunion/implant fracture }(\mathrm{n}=1) \\
\text { Screw cutout }(\mathrm{n}=1)\end{array}$ \\
\hline & Open reduction and internal fixation $(\mathrm{n}=19)$ & $42 \%$ & $\begin{array}{l}\text { Nonunion }(\mathrm{n}=2) \\
\text { Painful disease progression }(\mathrm{n}=3) \\
\text { Screw cutout }(\mathrm{n}=2) \\
\text { Implant fracture }(\mathrm{n}=1)\end{array}$ \\
\hline \multirow[t]{2}{*}{$\begin{array}{l}\text { Sarahrudi et al., } 2009 \\
\text { [28] }\end{array}$} & $\begin{array}{l}\text { Endoprosthetic reconstruction }(\mathrm{n}=23) \\
\text { Intramedullary nail }(\mathrm{n}=94)\end{array}$ & $\begin{array}{l}8.6 \% \\
3.2 \%\end{array}$ & $\begin{array}{l}\text { Periprosthetic fracture }(n=2) \\
\text { Nail breakage }(n=1) \\
\text { Screw loosening }(n=1) \\
\text { Periprosthetic fracture }(n=1)\end{array}$ \\
\hline & Open reduction and internal fixation $(\mathrm{n}=22)$ & $20 \%$ & $\begin{array}{l}\text { Periprosthetic fracture }(\mathrm{n}=2) \\
\text { Screw cutout }(\mathrm{n}=2)\end{array}$ \\
\hline Potter et al., 2009 [25] & Endoprosthetic reconstruction $(\mathrm{n}=61)$ & $9.8 \%$ & $\begin{array}{l}\text { Infection }(\mathrm{n}=3) \\
\text { Dislocation }(\mathrm{n}=4) \\
\text { Aseptic loosening }(\mathrm{n}=2) \\
\text { Symptomatic wear }(\mathrm{nv} 1)\end{array}$ \\
\hline Manoso et al., 2007 [17] & Endoprosthetic reconstruction $(\mathrm{n}=13)$ & $0 \%$ & None \\
\hline \multirow[t]{2}{*}{$\begin{array}{l}\text { Wedin and Bauer, } 2005 \\
\text { [33] }\end{array}$} & Endoprosthetic reconstruction $(\mathrm{n}=109)$ & $8.3 \%$ & $\begin{array}{l}\text { Pulmonary emboli }(n=2) \\
\text { Cerebrovascular event }(n=1) \\
\text { Dislocation }(n=15) \\
\text { Periprosthetic fracture }(n=4)\end{array}$ \\
\hline & $\begin{array}{l}\text { Open reduction and internal fixation/intramedullary nail } \\
\quad(\mathrm{n}=37)\end{array}$ & $16.2 \%$ & $\begin{array}{l}\text { Nonunion }(\mathrm{n}=3) \\
\text { Stress fracture }(\mathrm{n}=1)\end{array}$ \\
\hline Barwood et al., 2000 [4] & Intramedullary nail $(\mathrm{n}=45)$ & $\begin{array}{l}\text { Not } \\
\quad \text { reported }\end{array}$ & $\begin{array}{l}\text { Acute oxygen saturation and hypotension } \\
\quad(\mathrm{n}=11)\end{array}$ \\
\hline
\end{tabular}

hardware failures and a single periprosthetic fracture treated with cables as the only major complication. However, a much longer followup period and larger sample size is needed to detect less common complications and to develop a more complete safety profile for long stem cemented hemiarthroplasty.

Long stem cemented hemiarthroplasty appears to provide an adequate means for treating impending and actual pathologic fractures as a result of metastatic disease of the proximal femur in selected patients. Overall patient survival is comparable to that seen with other surgical approaches to metastatic bone disease. Patients with longer postoperative lifespans can be sufficiently palliated with substantial pain relief, return of mobility, and a higher degree of function provided there are no compounding variables related to their underlying disease negatively impacting recuperation. Even in patients with poorer prognosis, long stem cemented hemiarthroplasty may still be a useful means of pain control. Major complications were uncommon in this series, although a longer followup period is desirable to detect less common complications or potential hardware failure. Rigorous trials applying consistent indications and inclusion criteria are needed to directly compare long stem cemented hemiarthroplasty with other forms of endoprosthetic reconstruction as well as intramedullary nailing supplemented with 
polymethylmethacrylate and osteosynthesis with a platescrew construct and polymethylmethacrylate.

\section{References}

1. Algan SM, Horowitz SM. Surgical treatment of pathologic hip lesions in patients with metastatic disease. Clin Orthop Relat Res. 1996;332:223-231.

2. Alvi HM, Damron TA. Prophylactic stabilization for bone metastases, myeloma, or lymphoma: do we need to protect the entire bone? Clin Orthop Relat Res. 2013;471:706-714.

3. Assal M, Zanone X, Peter RE. Osteosynthesis of metastatic lesions of the proximal femur with a solid femoral nail and interlocking spiral blade inserted without reaming. J Orthop Trauma. 2000;14:394-397.

4. Barwood SA, Wilson JL, Molnar RR, Choong PF. The incidence of acute cardiorespiratory and vascular dysfunction following intramedullary nail fixation of femoral metastasis. Acta Orthop Scand. 2000;71:147-152.

5. Broos P, Reynders P, van den Bogert W, Vanderschot P. Surgical treatment of metastatic fracture of the femur improvement of quality of life. Acta Orthop Belg. 1993;59(Suppl 1):52-56.

6. Chandrasekar CR, Grimer RJ, Carter SR, Tillman RM, Abudu A, Buckley L. Modular endoprosthetic replacement for tumours of the proximal femur. J Bone Joint Surg Br. 2009;91:108-112.

7. Enneking WF, Dunham W, Gebhardt MC, Malawar M, Pritchard DJ. A system for the functional evaluation of reconstructive procedure after surgical treatment of tumor of the musculoskeletal system. Clin Orthop Relat Res. 1993;286:241-246.

8. Hage WD, Aboulafia AJ, Aboulafia DM. Incidence, location, and diagnostic evaluation of metastatic bone disease. Orthop Clin North Am. 2000;4:515-528, vii.

9. Hardes J, Gebert C, Schwappach A, Ahrens H, Streitburger A, Winkelmann W, Gosheger G. Characteristics and outcome of infections associated with tumor endoprostheses. Arch Orthop Trauma Surg. 2006;26:289-296.

10. Harvey N, Ahlmann ER, Allison DC, Wang L, Menendez LR. Endoprostheses last longer than intramedullary devices in proximal femur metastases. Clin Orthop Relat Res. 2012;470:684-691.

11. Hattori H, Mibe J, Matsuoka H, Nagai S, Yamamoto K. Surgical management of metastatic disease of the proximal femur. $J$ Orthop Surg (Hong Kong). 2007;15:295-298.

12. Herrenbruck T, Erickson EW, Damron TA, Heiner J. Adverse clinical events during cemented long-stem femoral arthroplasty. Clin Orthop Relat Res. 2002;395:154-163.

13. Issack PS, Barker J, Baker M, Kotwal SY, Lane JM. Surgical management of metastatic disease of the proximal part of the femur. J Bone Joint Surg Am. 2014;96:2091-2098.

14. Karnofsky DA, Abelmann WH, Craver LF, Burchenal JH. The use of the nitrogen mustards in the palliative treatment of carcinoma. With particular reference to bronchogenic carcinoma. Cancer. 1948;1:634-656.

15. Lane JM, Sculco TP, Zolan S. Treatment of pathological fractures of the hip by endoprosthetic replacement. J Bone Joint Surg Am. 1980;62:954-959.

16. Malek F, Somerson JS, Mitchel S, Williams RP. Does limb-salvage surgery offer patients better quality of life and functional capacity than amputation? Clin Orthop Relat Res. 2012;470:2000-2006.

17. Manoso MW, Frassica DA, Lietman ES, Frassica FJ. Proximal femoral replacement for metastatic bone disease. Orthopedics. 2007;30:384-388.
18. Menck H, Schulze S, Larsen E. Metastasis size in pathologic femoral fractures. Acta Orthop Scand. 1988;59:151-154.

19. Nakashima H, Katagiri H, Takahashi M, Sugiura H. Survival and ambulatory function after endoprosthetic replacement for metastatic bone tumor of the proximal femur. Nagoya J Med Sci. 2010;72:13-21.

20. Narazaki DK, de Alverga Neto CC, Baptista AM, Caiero MT, de Camargo OP. Prognostic factors in pathologic fractures secondary to metastatic tumors. Clinics (Sao Paulo). 2006;61:313320.

21. Oken MM, Creech RH, Tormey DC, Horton J, Davis TE, McFadden ET, Carbone PP. Toxicity and response criteria of the Eastern Cooperative Oncology Group. Am J Clin Oncol. 1982;5: 649-655.

22. Pala E, Henderson ER, Calabrò T, Angelini A, Abati CN, Trovarelli $G$, Ruggieri P. Survival of current production tumor endoprostheses: complications, functional results, and a comparative statistical analysis. J Surg Oncol. 2013;108:403-408.

23. Park DH, Jaiswal PK, Al-Hakim W, Aston WJ, Pollock RC, Skinner JA, Cannon SR, Briggs TW. The use of massive endoprostheses for the treatment of bone metastases. Sarcoma. 2007; 2007:62151.

24. Patterson BM, Healey JH, Cornell CN, Sharrock NE. Cardiac arrest during hip arthroplasty with a cemented long-stem component. A report of seven cases. J Bone Joint Surg Am. 1991;73: 271-277.

25. Potter BK, Chow VE, Adams SC, Letson GD, Temple HT. Endoprosthetic proximal femur replacement: metastatic versus primary tumors. Surg Oncol. 2009;18:343-349.

26. Price SL, Farukhi MA, Jones KB, Aoki SK, Randall RL. Complications of cemented long-stem hip arthroplasty in metastatic bone disease revisited. Clin Orthop Relat Res. 2013;471:33033307.

27. Randall RL, Aoki SK, Olson PR, Bott SI. Complications of cemented long-stem hip arthroplasties in metastatic bone disease. Clin Orthop Relat Res. 2006;443:287-295.

28. Sarahrudi K, Greitbauer M, Platzer P, Hausmann JT, Heinz T, Vecsei V. Surgical treatment of metastatic fractures of the femur: a retrospective analysis of 142 patients. J Trauma. 2009;66:11581163.

29. Selek H, Başarir K, Yildiz Y, Sağlik Y. Cemented endoprosthetic replacement for metastatic bone disease in the proximal femur. $J$ Arthroplasty. 2008;23:112-117.

30. Steensma M, Boland PJ, Morris CD, Athanasian E, Healey JH. Endoprosthetic treatment is more durable for pathologic proximal femur fractures. Clin Orthop Relat Res. 2012;470:920-926.

31. Steensma M, Healey JH. Trends in the surgical treatment of pathologic proximal femur fractures among Musculoskeletal Tumor Society members. Clin Orthop Relat Res. 2013;471:20002006.

32. Swanson KC, Pritchard DJ, Sim FH. Surgical treatment of metastatic disease of the femur. J Am Acad Orthop Surg. 2000; 8:56-65.

33. Wedin R, Bauer HC. Surgical treatment of skeletal metastatic lesions of the proximal femur: endoprosthesis or reconstruction nail? J Bone Joint Surg Br. 2005;87:1653-1657.

34. Wedin R, Bauer HC, Wersäll P. Failures after operation for skeletal metastatic lesions of long bones. Clin Orthop Relat Res. 1999;358:128-139.

35. Xing Z, Moon BS, Satcher RL, Lin PP, Lewis VO. A long femoral stem is not always required in hip arthroplasty for patients with proximal femur metastases. Clin Orthop Relat Res. 2013;471:1622-1627. 